\title{
A Temporal Assessment of Risk of Non-indigenous Species Introduction by Ballast Water to Canadian Coastal Waters Based on Environmental Similarity
}

\section{Ruixin Song}

Memorial University of Newfoundland

Yashar Tavakoli

Memorial University of Newfoundland

Sarah Bailey ( $\nabla$ sarah.bailey@dfo-mpo.gc.ca )

Department of Fisheries and Oceans https://orcid.org/0000-0003-3635-919X

Amilcar Soares

Memorial University of Newfoundland

\section{Research Article}

Keywords: Ballast water, environmental distance, environmental similarity, non-indigenous species, risk assessment, seasonal change

Posted Date: March 7th, 2022

DOI: https://doi.org/10.21203/rs.3.rs-1304354/v1

License: (c) (i) This work is licensed under a Creative Commons Attribution 4.0 International License. Read Full License 


\title{
A Temporal Assessment of Risk of Non-indigenous Species Introduction by Ballast Water to Canadian Coastal Waters Based on Environmental Similarity
}

\author{
Ruixin Song ${ }^{1}$, Yashar Tavakoli ${ }^{1}$, Sarah A. Bailey ${ }^{2^{*}}$ \\ and Amilcar Soares ${ }^{1}$ \\ ${ }^{1}$ Department of Computer Science, Memorial University of \\ Newfoundland, St. John's, NF, Canada. \\ ${ }^{2}$ Great Lakes Laboratory for Fisheries and Aquatic Sciences, \\ Fisheries and Oceans Canada, Burlington, ON, Canada. \\ *Corresponding author(s). E-mail(s): \\ Sarah.Bailey@dfo-mpo.gc.ca; \\ Contributing authors: rsong@mun.ca; yt3165@mun.ca; \\ amilcarsj@mun.ca;
}

\begin{abstract}
The environmental similarity scores between two locations are essential in ballast water risk assessment (BWRA) models used to estimate the potential for non-indigenous species introduction and guide management strategies aiming to minimize biodiversity loss and economic impacts. Previous BWRA models incorporate annual-scale environmental data, which may overlook seasonal variability. In this study, the differences in monthly sea surface temperature and salinity data were calculated at global ports and incorporated in a BWRA model. The environmental similarity scores were then calculated between the ballast water source and destination locations for ships arriving at Canadian coastal ports using monthly and annual-scale models for statistical comparison. As salinity and temperature vary seasonally in specific regions, there were significant differences in calculated environmental similarity risk values using annual and monthly-scale models. The results suggest that BWRA based on annual-scale data might underestimate environmental similarity
\end{abstract}




\section{Introduction}

The biological invasion process can be divided into several stages, including transport, introduction, establishment, and spread (Blackburn et al, 2011), all of which must be successfully passed for a NIS to be considered 'invasive'. Overcoming the barriers posed by these stages depends on multiple factors involving the traits of the species (Pyšek and Richardson, 2010), propagule pressure (Colautti et al, 2006; Briski et al, 2018), and environmental similarity (Barry et al, 2008). The multiple phases and interacting factors are challenging for risk assessment and proactive management, especially in aquatic ecosystems due to limited access and data standardization (Ojaveer et al, 2014, 2015).

Increases in shipping and other human activities across biogeographic regions has brought the issue of biological invasions to the forefront, with the main vectors for aquatic NIS introduction and spread being ballast water discharge and biofouling of ships (Keller et al, 2011b; Bailey et al, 2020b). Ballast water has been responsible for the transport and introduction of a variety of aquatic species across regions, including bacteria, fungi, plants, and animals (Ruiz et al, 1997; Keller et al, 2011b; Elçiçek et al, 2013). Therefore, a series of ballast water risk assessment (BWRA) tools were launched in the last few decades to guide ballast water management (BWM).

Environmental matching, species' biogeographical, and species-specific are three main approaches implemented in assessment tools for BWM (David et al, 2015). The species-based methods call for a multitude of data such as species' geographic distribution, life cycle, and physiological tolerances to assess their potential to survive in the new environment (Barry et al, 2008). As result, large datasets are required and it is vital to keep the information current. In contrast, the environmental matching strategy is a more general method, with more readily-available data that do not need frequent updating. Furthermore, the environmental matching approach enables the customization of environmental variables according to the assessment with lower model complexity, favoring the analysis of larger volumes of data.

Early BWRA models include a risk assessment in Nordic coastal waters based on salinity and climate factors (Gollasch and Leppäkoski, 1999), and the GloBallast BWRA (Clarke et al, 2003; Awad, 2004) led by the International Maritime Organization (IMO), which contains $34 \sim 37$ environmental parameters. More recent examples include an assessment of salinity match between donor and recipient ports for ships traveling between canals and oceans (David et al, 2013) and probabilistic models integrating an environmental distance 
method to target invasive species across regions (Seebens et al, 2013, 2016; Saebi et al, 2020).

In the models mentioned above, temperature and salinity were consistently included as environmental matching parameters, since they are considered the most critical factors contributing to the establishment of aquatic species (Barry et al, 2008; Keller et al, 2011a). A recent analysis of multiple variable groups in environmental matching assessments shows that including fewer, relevant variables outperformed applications with many variables and that temperature and salinity are the two critical factors for predicting the success of aquatic NIS (Bradie et al, 2015). However, temperature and salinity can be expressed as different measurements (e.g., minimum or maximum annual temperature (Hoek, 1982), annual average salinity, etc.). Since the publication of a highly influential model using annual-scaled environmental data (Keller et al, 2011a), many subsequent works have conducted environmental matching assessments following the same parameter set, including the BWRA tool currently used by Transport Canada (Bradie and Bailey, 2021; Etemad et al, 2021) that is the baseline model in this study. Although these models are stable and provide an indication of the likelihood of NIS introduction, the use of annual averages of temperature and salinity has limitations primarily related to insensitivity to seasonal variability, which potentially affects the probability that any introduced NIS can survive at a given time point.

Therefore in this study, we explore the seasonal variation of environmental factors using monthly temperature and salinity parameters, obtained from the World Ocean Atlas 2018 (Zweng et al, 2019; Locarnini et al, 2019), and the model proposed by (Bradie and Bailey, 2021). The outcomes of the two temporal scales are compared using a statistical approach with the null hypothesis that there is no difference in risk estimates using monthly vs. annual parameters in the calculation of environmental distance between ports.

\section{Materials and Methods}

\subsection{Fundamentals of the baseline risk model}

The baseline model used in this work is from (Bradie and Bailey, 2021) and is the practical tool used by Transport Canada for assessing ballast water risk (Etemad et al, 2021). Canada requires ships to submit ballast water reporting forms, declaring the source port of any ballast water to be discharged in Canadian waters, as well as details about management activities undertaken. The risk of each ship's ballast water is assessed through a comparison of environmental similarity between source and recipient ports (Bradie and Bailey, 2021) . The method works by normalizing the data with a z-score procedure applied to four environmental variables: (i) maximum, (ii) minimum, (iii) average temperature and (iv) average salinity. After normalization, a risk value is computed as the sum of euclidean distance values for these four environmental variables between the ballast water source and destination values.

More formally, the variables $V$ are: 


$$
V=\left\langle T_{\max }, T_{\min }, T_{\text {avg }}, S\right\rangle
$$

where $T_{\max }, T_{\min }, T_{\text {avg }}$ are maximum, minimum and average temperature, and $S$ is the average salinity of a source or destination location. The Euclidean distance is calculated between the four variables for ballast water source $\left(v_{s}\right)$ and destination $\left(v_{d}\right)\left(v_{s}, v_{d} \subset V\right)$ as follows:

$$
\operatorname{env} \text { _distance }\left(v_{s_{i}}, v_{d_{i}}\right)=\sqrt{\sum_{i=1}^{\mathrm{V}}\left(v_{s_{i}}-v_{d_{i}}\right)^{2}}
$$

Finally, risk categories and values were assigned based on the distribution of environmental distances between all pairwise permutations of ports on a global scale. The distribution of distance values is categorized by the following percentiles:

1. $(80 \%-100 \%)$ - very low risk with distance values over 4.020

2. $(60 \%-80 \%)$ - low risk and distance values ranging from 2.778 to 4.020

3. $(40 \%-60 \%)$ - moderate risk and distance values ranging from 1.5 to 2.778

4. $(20 \%-40 \%)$ - high risk and distance values ranging from 0.787 to 1.5

5. $(0-20 \%)$ - very high risk and distance values smaller than 0.787

Transport Canada agents can use these categories as part of prioritization to quickly identify ballast tanks that pose greater risk since categorical data are more easily interpreted than the numerical distance values. In this work, however, only numeric distance values are used in analysis. In this way, the data is continuously distributed and has a wider range of values that can be further analyzed and discussed.

\subsection{Extraction of seasonal-scale environmental data}

The data used for evaluating the seasonal variability in environmental variables (i.e., temperature and salinity) were compiled from two sources: (i) a list of 8,392 global shipping ports with positional coordinates (latitude and longitude) (Bailey et al, 2020a) and (ii) monthly sea surface temperature and salinity data from World Ocean Atlas 2018 (WOA 2018) (Locarnini et al, 2019; Zweng et al, 2019). The environmental variable values were available as a 1-degree grid (i.e., cells spaced by around $111 \mathrm{~km}$ ) from January to December.

The port data were matched with sea surface environmental variables based on closest geodesic distance. As the distance for some inland ports (e.g., Laurentian Great Lakes ports) to the nearest environmental data point was greater than 2 grid cells (approx. $222 \mathrm{~km}$ ), the analysis was restricted to coastal ports best represented by the data (any ports farther than 2 grid cells from nearest environmental data point were excluded). The match procedure framed 24 intermediate layers for 12 months' salinity and temperature data. Among these layers, the environmental data points missing surface values accounted for only $0.5 \%-3 \%$. Since the percentage of null-value points was relatively 
small, these points were dropped for each layer and the closest match procedure was rerun. The layers were then combined to create a port dataset with monthly environmental values.

The standard deviation (STDEV) of the 12 months' values was calculated at each port to examine how the environmental variables change during the year on a monthly scale. The data at each port were used to generate a raster layer, and an equal interval method was applied to categorize the values.

\subsection{Evaluation of monthly vs. annual risk models}

First, we extracted ballast water records (i.e., geolocation and dates when ballast water was taken up and discharged, by individual ballast water tanks) from the ballast water reporting forms for all ships entering Canadian waters in 2019 and 2020 from the Canadian Ballast Water Information System (Etemad et al, 2021). The tank records for the two years were processed separately to see if there is a similar/stable pattern across years. Next, we calculated environmental distances for each pair of ballast water source-recipient locations using the baseline model and the new seasonal model to generate the annual scale and monthly scale environmental distance values.

A density distribution plot was created for both models for visualization of differences between the models. Referring to the environmental distance-risk categorization detailed in Section 2.1, the data were queried for polarization values with environmental distances less than 0.787 (very high risk) and greater than 4.020 (very low risk).

To explore the risk changes, we first calculated the difference in distance values produced by the two scales, subtracting the annual-scale distance from the monthly-scale distance for each tank record: distance_diff $=$ env_distance $_{\text {month }}-$ env_distance $_{\text {year }}$. Then we divided these difference values into two sets, one with the positive distance difference values and the other with negative values. A positive distance difference value means that a port-pair was lower risk (had greater environmental distance) according to the monthly model. On the other hand, a negative distance difference means that the port-pair was higher risk (had lower environmental distance) according to the monthly model. To evaluate these two groups of data, we calculated the percentiles of positive and negative difference values separately. The percentiles $75 \%$ and $90 \%$ were selected as significance thresholds, which divide the significant difference values into the four categories described below:

1. (Positive difference greater than 1.586) - port-pairs with much lower risk if the monthly scale is used

2. (Positive difference between 0.835 and 1.586) - port-pairs with lower risk if the monthly scale is used

3. (Negative difference between -1.720 and -2.248) - port-pairs with higher risk if the monthly scale is used

4. (Negative difference lower than -2.248) - port-pairs with much higher risk if the monthly scale is used 


\section{Results}

\subsection{Seasonal changes in environmental variables}

The standard deviation of 12 months' environmental values at global shipping ports can be seen in Fig.1 and Fig. 2, for temperature and salinity, respectively. Fig. 1 shows that large seasonal temperature changes occur broadly and are greater in the northern hemisphere. Fig. 2 shows that the largest seasonal changes in salinity are mainly concentrated in the estuaries of large rivers (e.g., Amazon and Uruguay rivers in South America, Volga River in Eastern Europe).

\subsection{Comparison of environmental risks on yearly and monthly scales}

Ballast water source and destination locations were extracted from 87,951 tank records (7,242 trips) of ships arriving to Canadian waters in 2019 and 2020 (Etemad et al, 2021). After filtering the records to remove inland ports (ballast source or discharge location) and discharge locations outside of Canadian

\footnotetext{
${ }^{1}$ In some cases $r$ is the rank-biserial correlation calculated by $r=W / S$, where $S$ is the total rank sum (Kerby, 2014)
} 


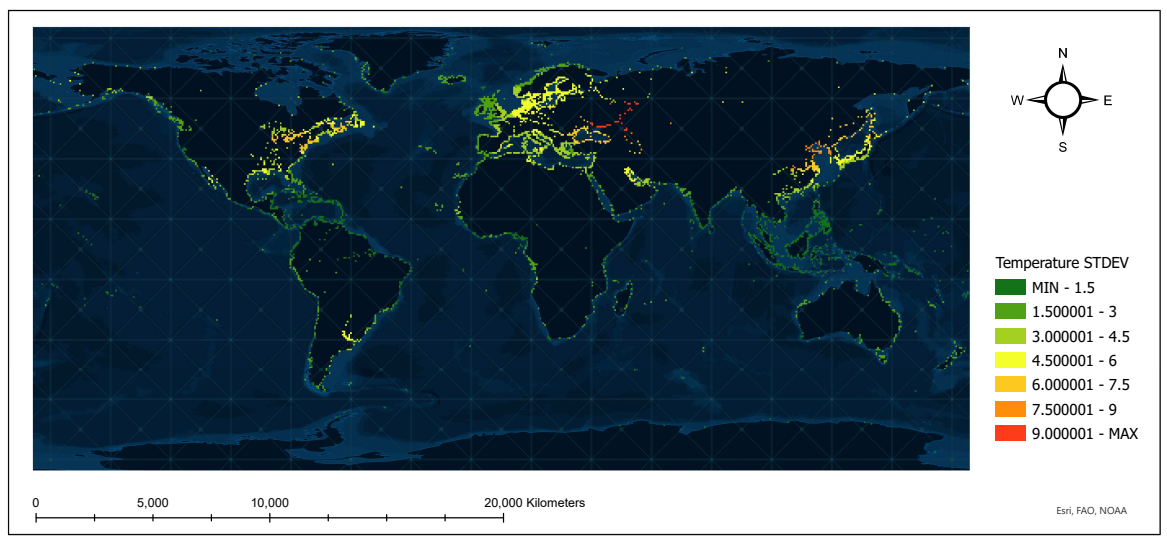

Fig. 1: Seasonal change in temperature at global shipping ports, illustrated by standard deviation (STDEV) of monthly mean values. STDEVs close to zero (green) indicate less temperature change during a year, while large STDEVs (red) means greater temperature change.

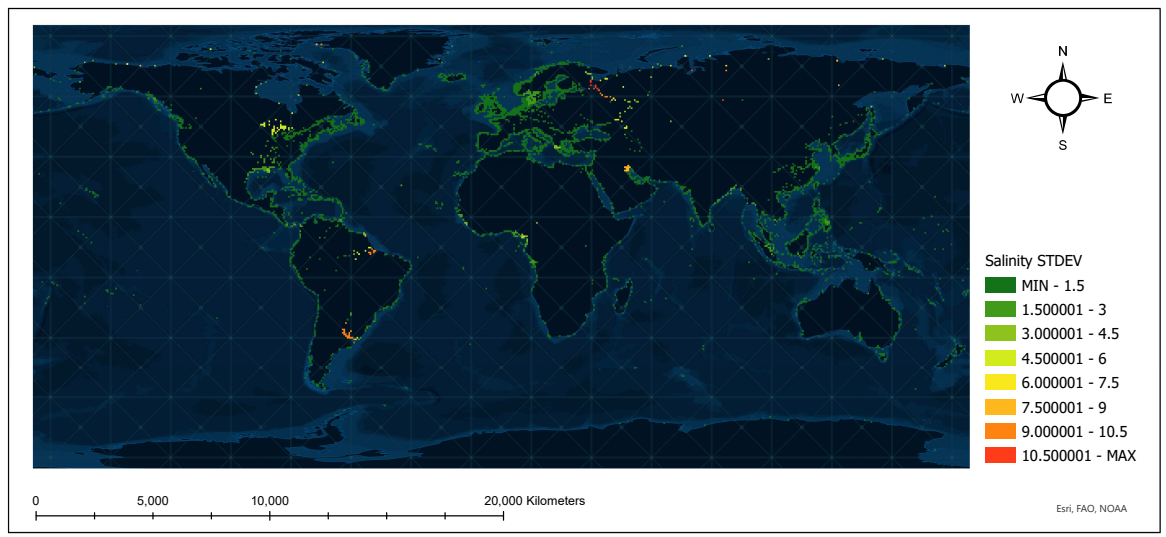

Fig. 2: Seasonal change in salinity at global shipping ports illustrated by standard deviation (STDEV) of monthly mean values. STDEVs close to zero (green pixels) indicate less salinity change during a year, while large STDEVs (red pixels) denote greater change in salinity.

water, 51,945 records (4,567 trips) remained for analysis. The environmental distances between the source-destination pair for each ballast tank record calculated using the model described in Section 2.1, using both annual and monthly variables, are shown in Fig. 3 as density distribution plots. The distributions in Fig. 3 generally follow the same pattern for both years, suggesting that the results are stable and can be generalized through time. The distribution is more polarized at the monthly scale (i.e., with more small and large 


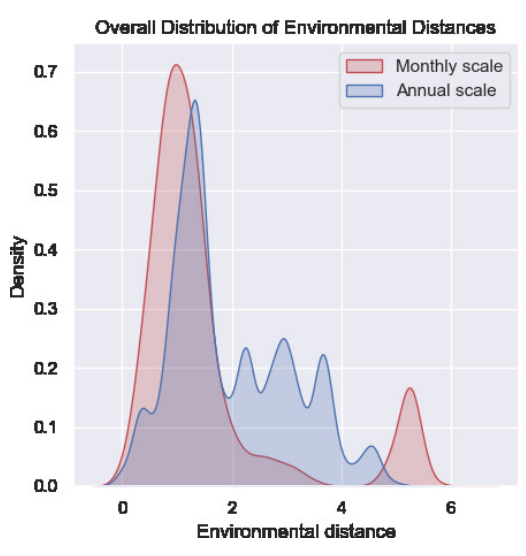

(a) 2019

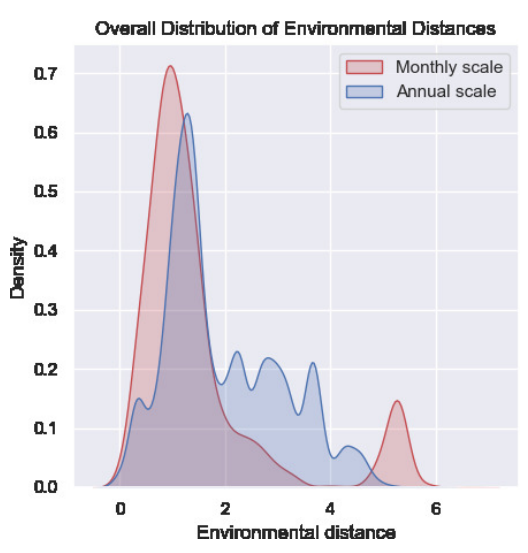

(b) 2020

Fig. 3: Distribution of environmental distance values by monthly and annual scales for ballast water discharges in Canada in 2019 and 2020.

values) for both years, indicating that a number of port-pairs become either more or less at-risk than estimated at the annual scale.

The polarization analysis revealed 17,291 records were very high risk, of which $50.03 \%$ and $49.96 \%$ were from the Atlantic and the Pacific regions, respectively, indicating that the high-risk discharge events are evenly located in these two regions. Analysis of the 7,490 very low risk records revealed that the Pacific region contributed $71.50 \%$ of this total. The proportion of very high-risk to very low-risk records increased using the model of monthly scale, with a ratio of nearly $7: 3$, compared to the ratio of $5: 7$ resulting from the annual-scale model. A distribution plot of these differences with the percentile categories can be seen in Fig. 4. In this study, the absolute difference values greater than $75 \%$ in both of the positive and negative subsets were considered to have a significant change in risk after using the monthly scale calculation (the green and red areas in Fig. 4).

Fig. 5 shows that several ports with significant average differences (i.e., in dark red and dark green) are mainly located in the Pacific and Atlantic regions, indicating that the average risk becomes much higher or lower for each ship destined to specific ports in these two regions. The ports in dark red whose average risk becomes much higher are Kitimat, Port McNeil, Port Alberni, Sechelt, New Westminster (Pacific); Havre St. Pierre, Paspebiac, South Brook, Holyrood (Atlantic). It is essential to point out that the ports with significant average differences shown in Fig. 5 do not represent the significance of differences in their regions, as an uneven distribution among ports clearly exists. Therefore, we also quantify and evaluate these differences by region and present the results of this comparison. 


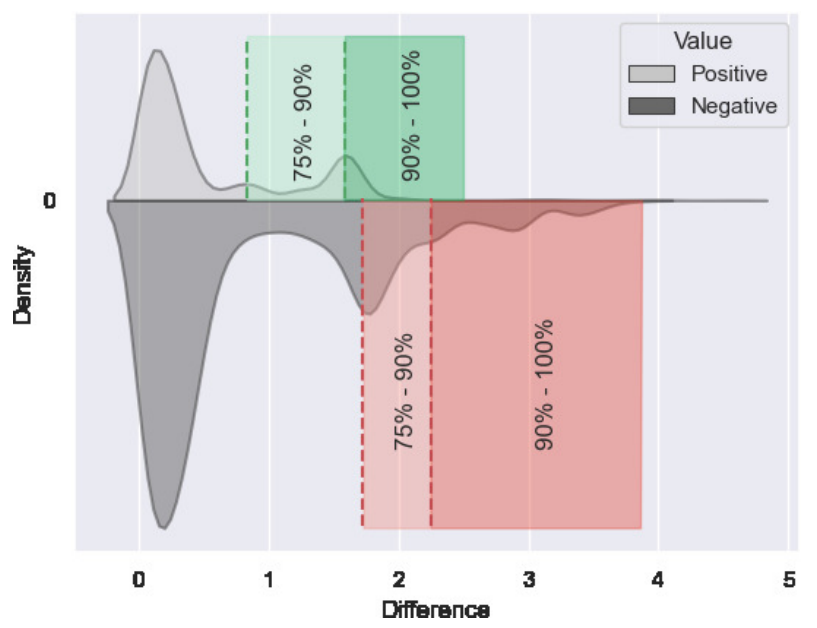

Fig. 4: A distribution plot of the differences between the environmental distances from the monthly and yearly risk models. The positive values above the zero-axis have lower risk scores by the monthly-scale model, while the negative values below are at higher risk. According to the port-pair categories in subsection 2.3, values in the light green and green areas are categorized as a lower and much lower risk; and in the light red and red areas are higher and much higher risk.

Table 1 shows the degree of differences between the paired samples of monthly and annual scales across regions, using the Wilcoxon signed-rank test with effect size $r$. For each region, the $r$ values of 2019 and 2020 are very similar (for their differences, 3 out of 4 are less than 0.05), suggesting that the regional contribution to the risk differences does not change much in the two years. Hence, the following analysis is applicable for both years.

The results shown in Table 1 for each region demonstrate that risk based on environmental distance changes considerably using monthly variables. The regions with large $r$ values indicate significant changes by using monthly scale variables in the model computation (e.g., Atlantic, Arctic). Although vessel discharges in the Pacific contributed nearly $50 \%$ of the 'very high risk' values in the polarization analysis, the effect size is small since this represents only a small proportion of the total discharges in the Pacific region. Fig. 6 shows the trend of change (i.e., distance values of the monthly scale being greater or smaller than the annual scale) by plotting the distribution of environmental distances using the distance values of the two years.

From Fig. 6, except for some outliers of high values in the Pacific region, the distance values of monthly scale generally become smaller in all the regions. This reveals that there are more environmental similarities between the source 


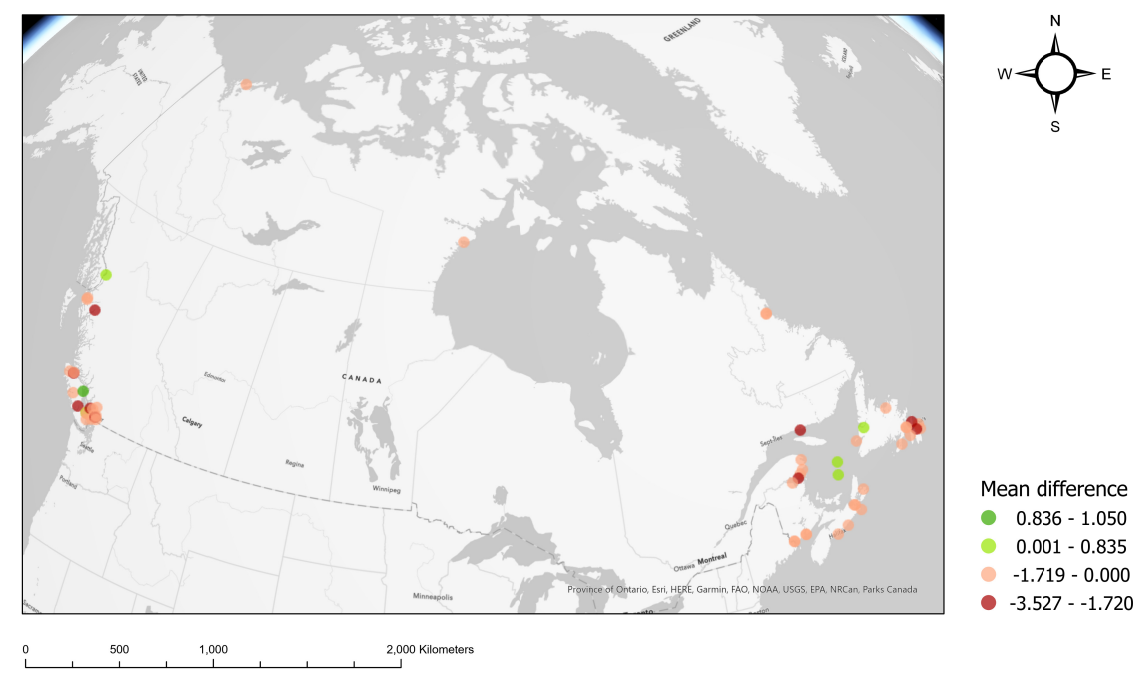

Fig. 5: The average differences between monthly and annual scale environmental distance values at destination ports. The difference values are attributed to four categories according to the percentile $75 \%$ significance thresholds. Ports marked with orange and dark red have higher risks, while those with light and dark green have lower risks using monthly-scale model.

Table 1: Wilcoxon signed-rank test result of ballast records in 2019 (left) and 2020 (right). $N$ is the sample size of the annual-scale and monthly-scale distances; $r$ is the effect size that quantitatively measure the difference between the two samples, ranging from 0 to 1 . Large effect size suggests significant difference. magnitude is used to qualify the differences by $r$ value: $0.1 \sim 0.3$ is considered "small", $0.3 \sim 0.5$ is considered "moderate", $0.6 \sim 1.0$ is categorized as "large".

\begin{tabular}{|c|c|c|c|c|c|c|}
\hline \multirow[b]{2}{*}{ Region } & \multicolumn{3}{|c|}{2019} & \multicolumn{3}{|c|}{2020} \\
\hline & $N$ & $r$ & magnitude & $N$ & $r$ & magnitude \\
\hline Pacific & 16574 & 0.282 & small & 18027 & 0.267 & small \\
\hline Atlantic & 8294 & 0.637 & large & 8989 & 0.640 & large \\
\hline Arctic & 45 & 0.863 & large & 16 & 0.845 & large \\
\hline
\end{tabular}

locations and destinations after employing the monthly-scale values into the baseline risk model. 


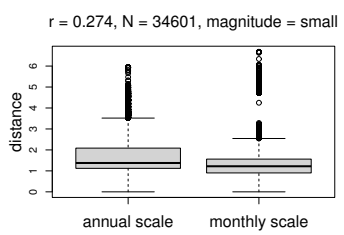

(a) Pacific

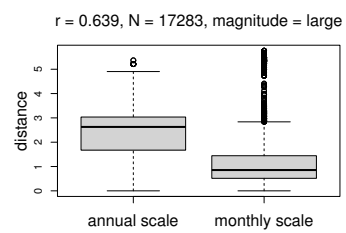

(b) Atlantic

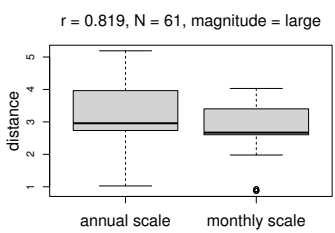

(c) Arctic

Fig. 6: Regional distribution of environmental distances. Fig (a)-(c) display the distribution of annual and monthly scale environmental distances for each region (Pacific, Atlantic, Arctic) respectively. $r$ is the effect size, $N$ is sample size of the paired distance values, magnitude is a criterion for $r$ value.

\section{Discussion}

Environmental matching is vital for ballast water risk assessment and management, enabling estimates of organism survival and establishment after release into new locations. Although there have been a number of previous studies implementing environmental matching in ballast water risk assessments (e.g., (Gollasch, 1996; Hilliard et al, 1997; Clarke et al, 2003; Awad, 2004; Keller et al, 2011a), none have analyzed the potential impacts of seasonal variability in their risk models. This work explored the seasonal variation of the most important environmental factors (i.e., temperature and salinity) at ports worldwide, demonstrating that the monthly variation of both variables can be large in some geographic regions, and that environmental risk of ballast water discharges into Canadian waters tend to be higher or lower using a monthlyscale model than an annual average model. Moreover, this variation is more pronounced in specific geographic regions, such as the Atlantic and Arctic, suggesting these regions deserve more attention to seasonal variability in any future NIS risk assessments.

The results of this study demonstrate how the seasonality of environmental characteristics may affect risk scores for NIS introduction through ballast water, which may have consequences for ballast water management decisions. Risk assessment can be used to prioritize limited resources, by focusing management actions on moderate- to high-risk activities (David et al, 2015). The results of this study show that assessments based on annual averages dampen risk outcomes, at least for the combination of ballast water source and discharge locations relevant to Canada. Ship discharges showing changes in risk scores with the same model based on seasonal (monthly) averages, especially those evaluated as low risk before but are high risk now, are worthy of more attention in future management activities.

There are several future works that could be conducted to overcome remaining knowledge gaps and limitations of this study. Firstly, ballast water is known to be an important vector for introduction of NIS to freshwater ecosystems 
such as the Laurentian Great Lakes (Briski et al, 2011; Bailey, 2015). Inland ports were excluded from this analysis due to the lack of environmental data near these ports in the World Ocean Atlas dataset; future work could include a seasonal assessment of environmental risk for ballast water discharges at these ports if suitable data are available elsewhere. In addition, if finer scale global data can be obtained for salinity, it would be desirable to further assess the temporal sensitivity of the environmental matching approach since salinity can fluctuate widely within a day at ports within estuaries subject to tidal influences. Moreover, the ballast tank records being fitted to models in this work span from 2019 to 2020, and are limited to discharges within Canadian waters. Although this research found similar patterns across the two years, the generality of the patterns observed in this study could be examined across a wider geographic scope and time span. Nonetheless, the results of this study suggest future evaluations incorporating ballast water uptake and discharge dates (or ships' departure and arrival dates, if the former are not available) can provide a more sensitive assessment of risk reflecting seasonal variability compared to an annual average risk model.

\section{Acknowledgements}

We thank Nader Zare for assistance with data extraction from Ballast Water Report Forms and providing Python code for the baseline risk model.

\section{References}

Awad A (2004) Ballast Water Risk Assessment: Port of Saldanha Bay Republic of South Africa: November 2003. International Maritime Organization

Bailey SA (2015) An overview of thirty years of research on ballast water as a vector for aquatic invasive species to freshwater and marine environments. Aquatic Ecosystem Health \& Management 18(3):261-268. https://doi.org/ $10.1080 / 14634988.2015 .1027129$

Bailey SA, Bradie JN, Ogilvie D, et al (2020a) Global port environmental data used for environmental distance calculations. Dryad, Dataset https: //doi.org/10.5061/dryad.69p8cz906

Bailey SA, Brown L, Campbell ML, et al (2020b) Trends in the detection of aquatic non-indigenous species across global marine, estuarine and freshwater ecosystems: A 50-year perspective. Diversity and Distributions 26(12):1780-1797. https://doi.org/10.1111/ddi.13167, URL https://onlinelibrary.wiley.com/doi/abs/10.1111/ddi.13167, https://arxiv.org/abs/https://onlinelibrary.wiley.com/doi/pdf/10.1111/ddi.13167

Barry SC, Hayes KR, Hewitt CL, et al (2008) Ballast water risk assessment: principles, processes, and methods. ICES Journal of Marine Science 
65(2):121-131. https://doi.org/10.1093/icesjms/fsn004

Blackburn TM, Pyšek P, Bacher S, et al (2011) A proposed unified framework for biological invasions. Trends in Ecology and Evolution 26(7):333-339. https://doi.org/10.1016/j.tree.2011.03.023

Bradie JN, Bailey SA (2021) A decision support tool to prioritize ballast water compliance monitoring by ranking risk of non-indigenous species establishment. Journal of Applied Ecology 58(3):587-595. https://doi.org/10.1111/ 1365-2664.13822

Bradie JN, Pietrobon A, Leung B (2015) Beyond species-specific assessments: an analysis and validation of environmental distance metrics for nonindigenous species risk assessment. Biological invasions 17(12):3455-3465. https://doi.org/10.1007/s10530-015-0970-8

Briski E, Bailey SA, MacIsaac HJ (2011) Invertebrates and their dormant eggs transported in ballast sediments of ships arriving to the canadian coasts and the laurentian great lakes. Limnology and Oceanography 56(5):1929-1939. https://doi.org/10.4319/lo.2011.56.5.1929

Briski E, Chan FT, Darling JA, et al (2018) Beyond propagule pressure: importance of selection during the transport stage of biological invasions. Frontiers in Ecology and the Environment 16(6):345-353. https://doi.org/10.1002/ fee. 1820

Clarke C, Facility GE, Organization IM, et al (2003) Ballast Water Risk Assessment: Port of Khark Island, Islamic Republic of Iran : Final Report. GloBallast monograph series, Programme Coordination Unit, Global Ballast Water Management Programme

Colautti RI, Grigorovich IA, MacIsaac HJ (2006) Propagule pressure: A null model for biological invasions. Biological Invasions 8(5):1023-1037. https: //doi.org/10.1007/s10530-005-3735-y

David M, Gollasch S, Leppäkoski E (2013) Risk assessment for exemptions from ballast water management - the baltic sea case study. Marine Pollution Bulletin 75(1):205-217. https://doi.org/10.1016/j.marpolbul.2013.07.031

David M, Gollasch S, Leppäkoski E, et al (2015) Risk Assessment in Ballast Water Management, Springer Netherlands, Dordrecht, pp 133-169. https: //doi.org/10.1007/978-94-017-9367-4_7

Elçiçek H, Parlak A, Cakmakci M (2013) Effect of ballast water on marine and coastal ecology. Journal of Selcuk University Natural and Applied Science (1):454-463 
Etemad M, Soares A, Mudroch P, et al (2021) Developing an advanced information system to support ballast water management. Management of Biological Invasions 13:1-13

Gollasch S (1996) Untersuchungen des Arteintrages durch den internationalen Schiffsverkehr unter besonderer Berücksichtigung nichtheimischer Arten. University of Hamburg

Gollasch S, Leppäkoski E (1999) Initial risk assessment of alien species in Nordic coastal waters. Nordic Council of Ministers

Hilliard RW, Walker S, Raaymakers S, et al (1997) Ballast Water Risk Assessment, 12 Queensland ports : stages 2 and $3 \mathrm{~A}$ report : selection \& environmental descriptions of overseas source ports. Ports Corporation of Queensland Queensland

Hoek CVD (1982) The distribution of benthic marine algae in relation to the temperature regulation of their life histories. Biological Journal of the Linnean Society 18(2):81-144. https://doi.org/10.1111/j.1095-8312. 1982.tb02035.x

Kassambara A (2021) rstatix: Pipe-Friendly Framework for Basic Statistical Tests. URL https://CRAN.R-project.org/package=rstatix, r package version 0.7 .0

Keller RP, Drake JM, Drew MB, et al (2011a) Linking environmental conditions and ship movements to estimate invasive species transport across the global shipping network. Diversity and Distributions 17(1):93-102. https: //doi.org/10.1111/j.1472-4642.2010.00696.x

Keller RP, Geist J, Jeschke JM, et al (2011b) Invasive species in europe: ecology, status, and policy. Environmental Sciences Europe 23(1):1-17. https: //doi.org/10.1186/2190-4715-23-23

Kerby DS (2014) The simple difference formula: An approach to teaching nonparametric correlation. Comprehensive Psychology 3:11.IT.3.1. https: //doi.org/10.2466/11.IT.3.1

Locarnini R, Mishonov A, Baranova O, et al (2019) World ocean atlas 2018, volume 1: Temperature. NOAA Atlas NESDIS 81 p 52

Ojaveer H, Galil BS, Gollasch S, et al (2014) Identifying the top issues of marine invasive alien species in europe. Management of Biological Invasions 5(2):81-84. https://doi.org/10.3391/mbi.2014.5.2.01

Ojaveer H, Galil BS, Campbell ML, et al (2015) Classification of nonindigenous species based on their impacts: Considerations for application in 
Pyšek P, Richardson DM (2010) Invasive species, environmental change and management, and health. Annual Review of Environment and Resources 35(1):25-55. https://doi.org/10.1146/annurev-environ-033009-095548

R Core Team (2021) R: A Language and Environment for Statistical Computing. R Foundation for Statistical Computing, Vienna, Austria, URL https://www.R-project.org/

Ruiz GM, Carlton JT, Grosholz ED, et al (1997) Global invasions of marine and estuarine habitats by non-indigenous species: Mechanisms, extent, and consequences. American Zoologist 37(6):621-632. https://doi.org/10.1093/ icb/37.6.621

Saebi M, Xu J, Grey EK, et al (2020) Higher-order patterns of aquatic species spread through the global shipping network. PLOS ONE 15(7):1-24. https: //doi.org/10.1371/journal.pone.0220353

Seebens H, Gastner MT, Blasius B (2013) The risk of marine bioinvasion caused by global shipping. Ecology Letters 16(6):782-790. https://doi.org/ 10.1111/ele.12111, URL https://onlinelibrary.wiley.com/doi/abs/10.1111/ ele.12111

Seebens H, Schwartz N, Schupp PJ, et al (2016) Predicting the spread of marine species introduced by global shipping. Proceedings of the National Academy of Sciences 113(20):5646-5651. https://doi.org/10.1073/ pnas. 1524427113

Zweng M, Reagan J, Seidov D, et al (2019) World ocean atlas 2018, volume 2: Salinity. NOAA Atlas NESDIS 82 p 50 


\section{Statements and Declarations}

\section{Funding}

This project was funded by Transport Canada, Fisheries and Oceans Canada, NSERC, and Memorial University of Newfoundland.

\section{Competing Interests}

The authors have no relevant financial or non-financial interests to disclose.

\section{Authors' Contributions}

Amilcar Soares and Sarah A. Bailey conceived and supervised the project. Amilcar Soares and Ruixin Song designed the methodology. Ruixin Song collected and analysed the data, and led the writing of the manuscript. Yashar Tavakoli assisted with statistical analyses. Sarah A. Bailey and Amilcar Soares enhanced and facilitated the manuscript. All authors contributed to the study and approved the final manuscript. 